\title{
Stomatal oscillations and the response of citrus trees to different irrigation strategies in northern Zimbabwe
}

\author{
Sebinasi Dzikiti (1) \\ Promotors: Raoul Lemeur(2), Kathy Steppe (2) \\ (I) Agricultural Meteorology Group, Department of Physics, University of Zimbabwe, \\ (2) Department of Applied Ecology and Environmental Biology, Ghent University
}

Public defence: 25 September 2007

Horticultural crops (e.g. citrus) play an important role to the economies of developing countries such as Zimbabwe. The sustainable production of citrus depends on the availability of adequate water throughout the year since citrus is an evergreen crop. The increasing competition for water between citrus growers, other crop growers, recreation, industrial and domestic users means that less water is becoming available for irrigating large citrus plantations, such as the Mazowe Citrus Estate in northern Zimbabwe. The problem of water shortage is worsened by the effects of global climate change which has led to an increased frequency and severity of droughts in Sub-Saharan Africa in recent years. Sustainable production of citrus, thus, requires not only the efficient management of the limited water resources, but also the development of new irrigation strategies which lead to improved water use efficiency. A typical irrigation strategy with the potential for improving the water use efficiency in tree crops is the partial root zone drying (PRD) strategy.

The primary goal of the $\mathrm{PhD}$ was to explore methods of improving water use efficiency in citrus plantations in northern Zimbabwe. Particularly, the potential application of bio-sensors for irrigation management in citrus plantations, e.g. the sap flow sensors, dendrometers (diameter variations) and the infrared thermometers (leaf-air temperature difference) was investigated. Much progress has been made on the use of these plant-based irrigation scheduling tools in the protected cropping industry (e.g. in greenhouses), but rarely in plantations. Information is also sparse on the response of citrus trees to the PRD irrigation strategy and this technique was also evaluated in the present study. The approach adopted involved two experimental phases, the first being a laboratory based approach, wherein the response of young potted orange trees, planted with a split root system to environmental variables, including manipulations of the soil water regimes, was quantified. The commonly grown cultivar of orange trees in Zimbabwe, the Navel cultivar [Citrus sinensis (L.) Osbeck] of the Baianinha selection was investigated. These trees were budded on two rootstocks, namely the Rough lemon [Citrus jambhiri (Lush.)] and the Troyer citrange [Citrus sinensis $\mathrm{x}$ Poncirus trifoliata L. Raf]. Results with the potted trees were then up-scaled to field conditions at Mazowe Citrus Estates in the second phase of the experimental campaign. The potential utility of the PRD irrigation strategy in improving the water use efficiency of citrus trees in northern Zimbabwe was evaluated. Carefully calibrated sensors were used to monitor the soil, plant and atmospheric variables both in the laboratory and in the field at Mazowe Citrus Estate.

Proper interpretation and use of the plant-based signals for water resource management requires a good understanding of the plant water relations of the specific crop. Thus, a substantial proportion of the thesis was devoted to understanding the plant water relations of the Navel orange trees. Measurements on the potted Navel orange trees revealed that the sap flow, stem diameter, 
leaf surface temperature and the leaf water potential all followed cyclic oscillations with a period ranging from 35-75 min depending on the rootstock. These oscillations were unquestionably a result of the periodic opening and closure of the stomata under clear sky conditions and with optimal soil water conditions. This phenomenon of stomatal oscillations, though first discovered many decades ago, still remains not yet fully explained. However, it is a common phenomenon occurring in more than 35 different plant species and many of them being crops of high commercial value e.g. some cultivars of beans, sunflower, cotton and citrus. In addition, point measurements of some aspect of the plant water status e.g. the leaf water potential has been used to make irrigation decisions e.g. on Navel orange trees, but with potentially large error margins given the large range of possible values that this variable can take under optimal environmental conditions.

The hypothesis that stomatal oscillations are mainly triggered by changes in plant water status, rather than by biochemical reactions in the leaves, was significantly advanced in this thesis. In addition, contrary to the widely held notion that changes in plant water status at leaf level are largely responsible for the generation of stomatal oscillations, we provided evidence that events elsewhere in the transpiration stream and distal to the leaves also play an important role in triggering stomatal oscillations. This was achieved by simultaneously tracking the water transport from the roots, stem and branches of the orange trees using sap flow sensors. Measurements of the stomatal conductance, to complement the sap flow measurements, were made on selected days. Parts of the transpiration stream where resistance to water transport was particularly high were isolated by cross-correlation of the water flow variables to quantify the time lags in water transport. The largest time lags resided downstream of the branch and up stream of the stem.

More importantly, also the resistance to water transport varied throughout the day, implying that the efficiency of water transport to the leaves also changed round the day. This led to transient internal water deficits, which appeared to control the stomatal aperture mediated by changes in the bulk leaf water potential. The cause of this short-term variation in the plant resistance is not well known although cavitation formation and its rapid reversal is a possible cause. The fact that the efficiency of water transport to the leaves played an important role in triggering the stomatal oscillations was further illustrated by comparing the characteristics of the stomatal oscillations for Navel orange trees budded on two rootstocks with contrasting water uptake capabilities, namely the Rough lemon and the Troyer citrange. A dynamic water transport model was developed and used to derive typical hydraulic constants (plant resistance and capacitance) of the transpiration stream of the Navel orange trees budded on these two rootstocks.

Experiments with the young potted Navel orange trees also revealed that the sap flow and stem diameter variation measurements were sensitive to variations in the soil water regimes and thus, they could potentially be used in the irrigation scheduling of these trees. Use of the leaf surface temperature was complicated by the leaf-rolling tendency of the orange trees under water stress making the effect of the water stress on the leaf surface temperature less clear. In addition, partially stressing the root zone of the potted orange trees (PRD) caused significant reductions in sap flow rates while stem growth rates were maintained. Up scaling these laboratory results to field conditions at Mazowe Citrus Estate confirmed that the transpiration rates of the Navel orange trees were indeed reduced under partial root zone drying (PRD) compared with the current growers' irrigation practice and with a well-watered treatment. Seasonal transpirational water savings of up to I Ml per hectare could potentially be achieved under partial root zone drying compared with the well-watered treatment and approximately $0.5 \mathrm{Ml}$ per hectare compared with the current irrigation practice by the growers at Mazowe Citrus Estate. However, small yield reductions also occurred under partial root zone drying when compared with the well-watered treatment mainly due to the 
high fruitset under the well-watered treatment. No significant differences in the yield occurred when the partial root zone drying treatment was compared with the current growers' irrigation practice implying that water use efficiency is increased under PRD. To maximize the water use efficiency at Mazowe Citrus Estate, Zimbabwe, it appears that a combination of the well-watered treatment and the partial root zone drying is needed but applied at different times. For instance, the well-watered approach could be adopted during flowering and fruitset to maximize fruitset (or to minimize fruit drop) and then switching to the partial root zone drying for the rest of the fruit growing season (to minimize transpirational losses). 